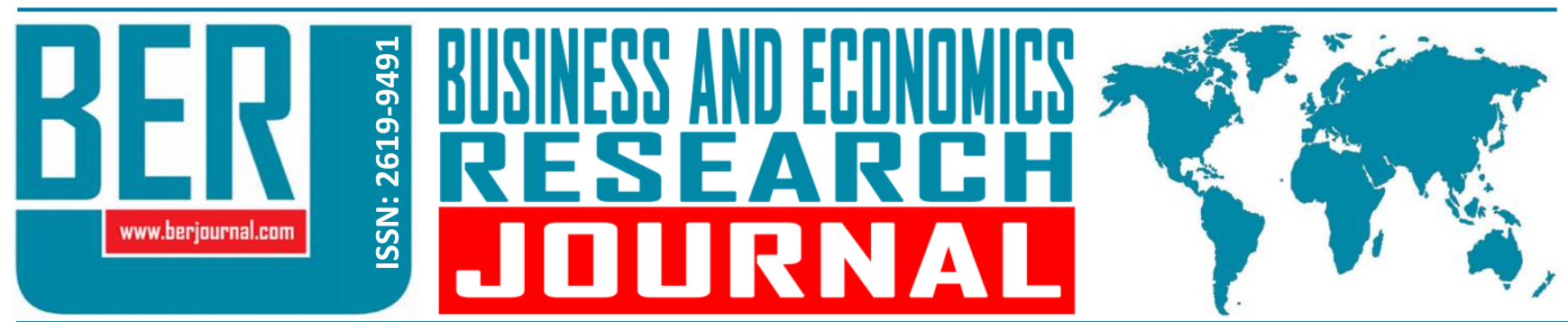

Business and Economics Research Journal Vol. 11, No. 1, 2020, pp. 247-259 doi: 10.20409/berj.2020.248

\section{Sürdürülebilir Kurumsal Marka Kavramı Üzerine Bir Literatür Çalışması ${ }^{1}$}

\section{Zeynep Arslan ${ }^{\mathrm{a}}$, Ebru Gokaliler $^{\mathrm{b}}$, Serafettin Arslan ${ }^{\mathrm{c}}$}

Öz: Bu çalışmanın konusunu kurumsal sürdürülebilirlik ve kurumsal marka kavramlarının entegrasyonu ile meydana gelen "sürdürülebilir kurumsal marka" kavramı oluşturmaktadır. Uluslararası literatürde bu kavram "sürdürülebilirliği temel değeri olarak vaad eden bir kurumsal marka" olarak tanımlanmıştır. Fakat bu tanım yüzeysel bulunarak bu çalışmada daha geniş kapsamlı bir tanım ve literatür taraması gerçekleştirilmiştir. Bu kavramın ulusal ve uluslararası literatürde çok detaylı olarak irdelenmemesi, bu çalıșmanın literatüre sağladığı özgün bir katkıdır. Dünya genelinde firmalar kurumsal marka stratejilerinin temeline sürdürülebilirliği yerleştirmeye başlamıştır. Bu bağlamda sürdürülebilir kurumsal markayı farklı perspektiflerden irdeleyerek Türkiye'de sürdürülebilir kurumsal marka yaratmak isteyen firmalar için bir yol haritası oluşturulması amaçlanmaktadır. Bu durumun sürdürülebilir kurumsal marka olma hedefinde şirketler için bir araç olacağı düşünülmektedir.

\section{A Literature Study on the Sustainable Corporate Brand Concept}

Abstract: The subject of this research; the concept of "sustainable corporate brand" that comes to life with the integration of corporate sustainability and corporate brand concepts. In the international literature, this concept is defined "as a corporate brand that promises sustainability as a core value". However, since this definition is not comprehensive, a broader definition has been made and a comprehensive literature search has been carried out. The fact that this concept is not examined in detail in the national and international literature is a unique contribution of this study to the literature. Sustainability in the world has begun to be placed at the core of corporate brand strategies. In this context, by examining from different perspectives of sustainable corporate brand, it is aimed to draw a road map for companies that want to build the sustainable corporate brand in Turkey. This situation is considered to be a tool for companies aiming to become a sustainable corporate brand.

\section{Anahtar Sözcükler:}

Kurumsal Marka, Kurumsal Sürdürülebilirlik, Sürdürülebilir Kurumsal Marka, Kurumsal Teori, Meşruluk

JEL: M14, M31

$\begin{array}{ll}\text { Geliş } & : \text { 16 Eylül } 2019 \\ \text { Düzeltme } & : 05 \text { Kasım } 2019 \\ \text { Kabul } & : 09 \text { Aralık } 2019 \\ & \\ \text { Tür } & : \text { Kuramsal }\end{array}$

Keywords: Corporate Brand, Corporate Sustainability, Sustainable Corporate Brand, Corporate Theory, Legitimacy

JEL: M14, M31

Received : 16 September 2019 Revised : 05 November 2019 Accepted : 09 December 2019

Type : Conceptual

PhD., Independent Researcher, zeynep.luleci@yahoo.com, (ORCID: 0000-0003-3379-396X)

b Assoc.Prof., PhD., Yaşar University, Faculty of Communication, Public Relations and Advertising Department, ebru.gokaliler@yasar.edu.tr (ORCID: 0000-0002-4134-8447)

PhD., CPA, serafettin.arslan@email.com (ORCID: 0000-0002-4060-7910) 


\section{Giriş}

Dünyada hızlı bir nüfus artışı ve kaynakların hızlı bir şekilde tüketilmesi söz konusudur. Bu tüketim, doğanın kendi kendini yenileme hızından daha fazladır. Bir diğer ifadeyle, doğal kaynaklar ve canlılar her geçen gün yok olmaktadır. Öyle ki, Dünya Vahşi Yaşam Fonu'nun verilerine göre 1970-2010 yılları arasında dünya üzerinde memeliler, kuşlar, sürüngenler ve balık popülasyonunda $\% 50$ düşüş meydana geldiği belirtilmektedir. Bilim insanları nüfus artışı, sanayileşme, fosil yakıt kullanımı, motorlu araçların yaydığı gazlar ile iklim ısındıkça, karbondioksiti emme özelliği olan bitkilerin bu özelliklerini yitirip, sera etkisine sahip gazları üretmeye başlayacağını ve insanların yanında artık bitkilerin ürettikleri karbon emisyonlarının da havaya ekleneceğini belirtmektedir (Gerber vd. 2013). Bunlar dünya sağlığının zaman geçtikçe kötüye gittiğinin sinyalleridir ve dünya üzerinde bu konulara odaklanan insanların, sivil toplum kuruluşlarının ve ülkelerin sayısı artmaktadır (Gemmill ve Bamidele-ızu, 2002; Allard ve Martinez, 2008). Bu doğrultuda, farklı paydaş gruplarının katkıları ile hazırlanan "Ortak Geleceğimiz" isimli Bruntland Raporunda sürdürülebilirlik, "bugün ihtiyaçları gelecek nesillerin ihtiyaçlarını tehlikeye atmayacak şekilde karşılamak" olarak tanımlanmıştır. Bu tanım ise insan ihtiyaç ya da isteklerine odaklandığı ve doğal çevre konusunda yeterince açık olmadığı için eleştirilmektedir (Diesendorf, 2000: 23). Bu eleştiriden yola çıkarak Diesendorf (2000: 23), "Sürdürülebilir kalkınma, doğal çevreyi ve sosyal eşitliği koruyan ve geliştiren ekonomik ve sosyal kalkınma türlerini içerir" tanımını yapmıştır.

Doğal ve sosyal çevrenin korunması hususu ön plana çıkarken, hükümetlerin gücünün yetmediği birçok faaliyet artık işletmelerden beklenmektedir. Çünkü işletmeler pazarlama ve reklam faaliyetleriyle tüketimi arttırarak, hammadde temininden ambalajlara ve ürünün dağıtımına kadar çevreye hatırı sayılır bir etki bırakmaktadır. Gönüllü olarak ya da farklı paydaş gruplarından gelen baskılar nedeniyle, her geçen gün daha fazla firma kurumsal sürdürülebilirlik alanına dahil olmaktadır. Tabi firmalar açısından sürdürülebilirliğe yönelmek kadar, bu alandaki stratejilerin iletişiminin yapılabilmesi de gereklidir. Çünkü yapılan araştırmalar firmaların sürdürülebilirlik yatıımları fazla olsa da paydaşlar tarafından sürdürülebilirlik algısının düşük olabileceğini ortaya koymaktadır (Peloza, 2012). Bu doğrultuda sürdürülebilirlik faaliyetlerinin gerçekleştirilmesi kadar onun çoklu paydaşlara doğru şekilde iletilmesi de toplum nezdinde itibarın artması açısından oldukça önem kazanmaktadır. İşte bu noktada sürdürülebilir kurumsal marka, firmaların sürdürülebilirlik stratejilerini çoklu paydaşlarına iletmeleri için bir arayüz oluşturmaktadır (Leitch ve Richardson, 2003). Firmalar tarafından sürdürülebilirliğin önemi anlaşılmaya ve bu konuda faaliyetler yapılmaya başlansa da, genellikle sürdürülebilirlik, kurumsal markadan ayrı tutulmakta ve bu da sürdürülebilirliğin kurum kültürü ve stratejisine entegre edilememesine neden olmaktadır. Halbuki sürdürülebilir kurumsal markanın paydaşlar tarafından gerçekçi şekilde algılanması için bu entegrasyonun gerçekleştirilmesine dikkat edilmelidir. Çünkü zaman içinde paydaşlar tarafından samimi bulunmayan firmaların marka imajları zedelenecek ve itibar kaybı yaşayacaklardır.

Bu çalışma sürdürülebilir kurumsal marka kavramının ulusal ve uluslararası literatür kapsamında çok detaylı olarak irdelenmemesi nedeniyle literatüre katkı sağlaması açısından önem taşımaktadır. Dünya genelinde kurumsal markalar stratejilerinin temeline sürdürülebilirliği yerleştirirlerken, Türkiye özelinde şirketler sürdürülebilirliği henüz yalnızca bir iletişim vaadi olarak değerlendirmektedir. Ayrıca, sürdürülebilirliği stratejilerinin temeline alarak sürdürülebilir kurumsal marka adını hakeden şirket sayısının az olduğu belirtilebilmektedir. Bu bağlamda sürdürülebilir kurumsal markayı farklı perspektiflerden irdeleyerek marka ve sürdürülebilirlik entegrasyonu için bir yol haritası çizilmesi amaçlanmaktadır. Bu durum da özellikle Türk literatüründe bir eksik olan sürdürülebilir kurumsal marka olma hedefinde şirketler için bir araç olacağı düşünülmektedir.

\section{Kurumsal Sürdürülebilirlik}

Sürdürülebilir kalkınmanın odak noktaları olan sosyal ve çevresel konularda işletmelerin operasyonlarını ve paydaşlarıyla etkileşimini temsil eden (van Marrewijk ve Were, 2003) kurumsal sürdürülebilirlik, işletme faaliyetlerinin sosyal, çevresel ve ekonomik sürdürülebilirlik boyutlarıyla kavramsallaştırılabilir (Roca ve Searcy, 2012). Dyllick ve Hockerts'e (2002: 131) göre kurumsal 
sürdürülebilirlik; "Gelecek paydaşların ihtiyaçlarını karşılamayı kısıtlamayacak şekilde firmaların çalışanlar, müşteriler, baskı grupları ve topluluklar gibi doğrudan ya da dolaylı paydaşlarının ihtiyaçlarını karşılamaktır".

Kurumların sürdürülebilir olması için sürdürülebilir kalkınma konusunda iki konuya dikkat etmesi gerekir (Dyllick ve Hockerts 2002: 136). Ilk olarak, yöneticiler, eko-verimlilik kapsamında kurumsal sürdürülebilirlik için doğaya özen göstermeli, doğal sermayeyi verimli kullanmalıdır. Eko-verimlilik, rekabetçi fiyatla ürün ve hizmetleri sunup insan ihtiyaçlarını ekolojik etkiyi azaltarak ve kaynaklara fazla yüklenmeyerek sunmaktır (DeSimone ve Popoff 1997: 42). İkincisi; firma sürdürülebilirlik için topluma özen göstermelidir. Diğer bir ifade ile sosyal gelişim ve esenliğe katkıda bulunmalıdır.

Kısaca ifade etmek gerekirse, sürdürülebilirliğin işletmeler tarafından ele alınması kurumsal sürdürülebilirlik olarak tanımlanmaktadır (Dunphy, Griffiths ve Benn, 2003; Baumgartner ve Ebner, 2010). Burada esas olan, işletmelerin bütüncül bir yaklaşımla hareket ederek, kurumsal sürdürülebilirliğin üç boyutu olan ekonomik, çevresel ve soysal alanlarda değer yaratmak üzere yaptıkları faaliyetler ile ürettikleri ürün ve hizmetlerin paydaş beklentileri ile uyumlu hale gelmesini sağlamalarıdır (Arslan ve Albayrak, 2019). İşletmelerin uzun vadeli ekonomik faydalar üzerinde durması ve onları kısa vadede riske atacak sosyal ve çevresel olumsuz faaliyetlerden kaçınması, sürdürülebilirlik hedefine ulaşmalarını sağlayacaktır (Porter ve Kramer, 2006).

İşletmeler, toplumda şekillenen ve sosyal amaçların gerçekleşmesi için birer araç olarak, iş yapış şekillerini değiştirerek, kaynakları dikkatli kullanarak, faydalı ürün ve hizmetler üreterek yeni durumlara esnek yanıtlar verebilmelidir (Dunphy, Griffiths ve Benn 2003: 4). Diğer bir ifade ile, işletmelerin yalnızca müşteri beklentilerini tatmin etmek üzere ürün ya da hizmet üretmekle yetinmemeleri, aynı zamanda meydana getirdikleri çevresel ve sosyal zararları minimuma indirmek üzere aktif çalışarak sürdürülebilirlik liderleri grubuna dahil olmaları, onlardan beklenenler arasındadır (Hahn ve Scheermesser, 2006). Ancak paydaşlardan gelen sosyal ve çevresel alandaki bu beklentileri iyi anlayıp zamanında yanıt verebilen işletmelerin lider konumuna gelerek rekabet avantajı kazanmaları mümkün olacaktır (Arslan, 2019).

Sürdürülebilirlik bakış açısı ile işletmelerden genel olarak toplumun refahını geliştirmesi (Schwartz ve Carroll, 2008), sosyal, çevresel ve ekonomik meseleleri yönetme ve paydaş düşünceleri hususunda daha hassas davranmaları beklenmektedir (Hahn ve Scheermesser, 2006). Çevre ve toplum konusundaki ana motivasyon kaynağı ister hükümet düzenlemeleri, isterse paydaş baskısı ya da ekonomik kar elde etme olsun, firmaların sosyal, ekonomik ve çevresel etkilerini yönetmeleri kaçınılmazdır. Tabi ki sürdürülebilirliği benimsemeyen firmalar da mevcuttur ve hatta son bir araştırmaya göre sürdürülebilirliği benimseyen ve benimsemeyen firmalar arasındaki boşluğun giderek arttığı (BCG \& MIT, 2011: 22) ve sürdürülebilirliği benimsemeyen firmaların paydaşlar tarafından cezalandırıldığı belirtilmektedir (Peloza, 2012: 76). Sürdürülebilirliği benimseyen firmalar için ise vizyon ve iletilen çekirdek değerlerin önemli olduğu kabul edilmekte, fakat bunun yanında sosyal, çevresel ve ekonomik alana ilişkin taahhütlerin hem sözcükler hem de eylemlerle sürekli olarak iletilmesi gerekmektedir (Epstein ve Buhavoc, 2014: 7).

Günümüzde sürdürülebilirliğin paydaşlar tarafından takip edilmesi, gelişen iletişim teknolojileri ile birlikte sürdürülebilirliği benimseyip benimsemeyen firmaların kolaylıkla görülebilmesi, markaların itibarlarını korumalarını zorlaştırmaktadır. Çünkü herhangi bir hata söz konusu olduğunda paydaşlar, firmaları cezalandırmakta ve uzun sürede oluşan itibar bir defalık olay ile bile kaybedilebilmektedir (Peloza, 2012). Bu nedenle işletmelerin sürdürülebilirlik meselelerine odaklanmasının özellikle meşrulaşma ile bağlantılı olduğu söylenebilir. İzomorfizmin, daha düşük itibara sahip firmaların, meşruluk ve itibarında pozitif etkiye sahip olduğu belirtilmektedir (Deephouse ve Carter, 2005). Çünkü paydaşlar, işletmelerin sürdürülebilirlik ile ilgili normlara ve değerlere uygun faaliyet gösterdiğini anladığında işletmeler meşruluk kazanabilir. Buna ek olarak meşruluk, dinamik bir kavram olarak firmanın itibarından da kötü etkilenebilir. Diğer bir ifade ile işletmeler paydaşlarına verdiği sözü tutmadığında, bir bakıma sözleşmeyi ihlal ettiğinde meşru olmadığı yönünde algılanır. Tıpkı BP’nin "Petrolün Ötesinde" sloganı ile güncel trendlere uyup "yeşilboyama” yapması gibi. Özellikle aynı sektörde yer alan firmaların benzer davranış kalıplarını izlemeleri, izomorfizm olarak adlandırımaktadır (DiMaggio ve Powell, 1991; Barley ve Tolbert, 1997). 
Asıl problem ise firmalar için yalnızca sürdürülebilirliği benimsemek yetmemekte, bunu çoklu paydaşlara doğru bir şekilde iletmeleri gerekmektedir (Peloza, 2012). Bu noktada, kurumsal çevresel ilkeler, kodlar ve programlar geliştirmeye çalışan güçlü markalar çevresel faktörleri temel operasyonlarına, ürünlerine ve tedarik zincirlerine tanımlamak ve entegre etmek için rekabet ederek sonuçta sürdürülebilirliği en değerli varlığına yani markalarına bağlamaktadır (Dauvergne ve Lister, 2011; Arslan, 2019). Hatta sürdürülebilir firmaların, paydaşların dikkatini çeken önemli konularda kurumsal markalarını ön plana çıkaracak ve paydaşların zihninde sürdürülebilirlik alanında bir konum elde etmelerini sağlayacak bazı kavramlara sürdürülebilirlik raporalarında değinildiği belirtilmektedir (Arslan ve Albayrak, 2019). Bu durum sürdürülebilirlik faaliyetlerinin paydaşlar tarafından algılanması adına, kurumsal markanın önemli bir konumda olduğunu ifade etmektedir. Bu noktada kurumsal marka, firmaların sürdürülebilirlik faaliyetlerini çoklu paydaşlarına iletmeleri için bir arayüz olarak tanımlanabilir (Leitch ve Richardson, 2003).

\section{Sürdürülebilir Kurumsal Marka}

Kurumsal marka, işletmelerin çoklu paydaşları üzerinde kimlik tabanlı örgüt kültürü ve algıları oluşturmak üzere, kurumsal marka değerlerini anlamak, yönetmek ve iletmek olarak tanımlanmaktadır (Hatch ve Schultz, 2003; Lawer ve Knox, 2004). Bu kavram, hem iç hem de dış paydaşlara odaklanan yapısı ile yönetimin vizyon, kültür ve imaj uyumunu sağlamasını (Hatch ve Schultz, 2001; Hulberg, 2006) ve çoklu paydaşlarla etkileşimi (Leitch ve Richarson, 2003; Abratt ve Kleyn, 2012) gerektirmektedir. Bu doğrultuda kavram; kurum ve çoklu paydaşları arasında bir değer sözleşmesi (Balmer, 2001), kurumsal söz ya da anlaşma etrafında dönen bir kimlik türü (Balmer ve Greyser, 2003), bir iletişim arayüzü (Leitch ve Richardson, 2003), kurumsal iletişim aracılığıyla iç ve dış paydaşlara iletilen örgütsel ifadeler (Brown ve Dacin, 1997), çekirdek değerler vasıtasıyla paydaşlara iletilen organizasyon ifadelerinin toplamı olarak tanımlanmaktadır (Christiansen ve Askegaard, 2001).

Kurumsal markaların sürdürülebilir ve şeffaf uygulamaları benimsemesi ile ilgili gelişmekte olan paydaş talebine rağmen, çok az yazar sürdürülebilirliği markalamaya bağlamıştır (Gad. ve Moss, 2008; Cooper, 2009; Stuart, 2011; Rindell, Svenson, Mysen, Bilström ve Wilen, 2011; Lindgreen, Xu, Maon ve Wilcock, 2012; Gupta ve Kumar, 2013; Erdil, 2013; Hutchinson, Singh, Svensson ve Mysen, 2013; Rappers, 2013; Ruzzier, Petek ve Ruzzier, 2015). Bu iki kavramın birleşimi işletmelerde marka yönetimi stratejileri geliştirilmesine yardımcı olmaktadır (Cooper, 2009). Hatta bağımsız bir araştırma şirketinin yaptığı araştırmaya göre firmaların büyük çoğunluğu sürdürülebilirlik iletişimi stratejilerine yatırım yapmakta, fakat sürdürülebilirliği kurumsal markaya entegre etmedikleri için somut faydalar elde edememektedir (Vertandix, 2013). Zaten literatürde, bu alandaki hassasiyetin artması ile marka yöneticileri, tedarik zinciri üyeleri, tüketiciler ve diğer paydaşların, mümkün olan en iyi uygulamalara varmak ve sürdürülebilir bir marka yaratmak için birlikte çalışmaları önerilmektedir (Lindgreen, Xu, Maon ve Wilcock, 2012; Barrow, 2013).

Sürdürülebilirlik ve kurumsal marka kavramlarının biraraya gelmesiyle oluşan sürdürülebilir kurumsal marka kavramı; "sürdürülebilirliği temel değeri olarak vaad eden bir kurumsal marka" olarak tanımlanmaktadır (Stuart, 2011: 139). Esasında bu kavram, yalnızca işletmelerin sürdürülebilirlik faaliyetlerinin çoklu paydaşlara iletilmesini ifade etmemektedir. Sürdürülebilirliğin çekirdek strateji olarak ele alınmasını ve firmanın stratejiden kültüre tüm alanda sürdürülebilirliği özümsemesini ve gerçek uygulamalar sayesinde yeşil boyama yapan firmalardan farklı olarak çoklu paydaşlarla iletişim ve işbirliği içinde olmayı ifade etmektedir. Bu doğrultuda literatür incelendiğinde, Stuart'ın (2011) yapmış olduğu sürdürülebilir kurumsal marka tanımının geliştirilme ve sürdürülebilir kurumsal marka yaratmak isteyen firmalar için daha net bir şekilde ifade edilmesi ihtiyacı ortaya çıkmıştır. Buna göre sürdürülebilir kurumsal marka "sürdürülebilirliği kurumsal hikayesine entegre ederek, başta çalışanların bu stratejiyi özümsemesini sağlayan, çalışanlar vasıtasıyla onu kültürüne entegre eden ve tedarik zincirinden sunduğu ürün ve hizmetlere varıncaya kadar paydaşlarına sosyal, çevresel ve ekonomik alanda çeşitli değerler sunarak onların zihninde bir konum elde eden marka" olarak tanımlanmıştır.

Çoklu paydaşların sürdürülebilirlik konusundaki hassasiyetleri ile birlikte, küresel firmalar arasında çevreci faaliyetler; kısıtlı uygumalardan ziyade, işletme stratejisine entegre edilerek daha proaktif bir şekilde yürütülmeye başlanmıştır. (Bansal ve Hoffman, 2011). Günümüzde hala bunu yalnızca halkla ilişkiler çalışması 
olarak yapan firmalar olabilmektedir (Dauvergne ve Lister, 2011). Fakat söz konusu sürdürülebilir kurumsal marka olduğunda, kurumsal sürdürülebilirlik artık daha ölçülebilir hedefler ile bağımsız gruplar tarafından kontrol edilmekte ve yaşam döngüsü değerlendirme, tedarik zinciri takibi, eko sertifikalar ve sürdürülebilirlik raporlamaları gibi ölçülebilir uygulamalarla çekirdek işletme stratejisine entegre edilmektedir.

Hem sürdürülebilirlik hem de kurumsal marka kavramlarının çok boyutlu oluşu, bu iki kavramı kapsayan sürdürülebilir kurumsal marka kavramının da çok boyutlu şekilde ele alınması anlamına gelmektedir. Literatüre dayanarak sürdürülebilir kurumsal marka kavramı için çeşitli özellikler ve buna bağı önermeler ortaya çıkarılabilir (Belz ve Riediger, 2009; Stuart, 2011; Dauvergne ve Lister, 2011:1; Peloza, 2012; Vertandix, 2013; Czinkota, Kaufmann ve Basile, 2014). Bu özelliklerin, firmaların kurumsal sürdürülebilirliği "yeşil boyama" yapan firmalardan farklı olarak, gerçekten özümsemesini sağlamak üzere yol gösterici olacağı düşünülmektedir. Sürdürülebilir kurumsal marka kavramı kapsamında, firmaların sürdürülebilirliği vizyon, misyon ve değerlerden oluşan kurumsal hikayelerine, çalışanların özümsemesi için kültürlerine ve tutarlı olmak adına imaja entegre etmeleri, gerekiyorsa kurumsal imajın yeniden markalandırılması, paydaşlarla işbirliklerinin geliştirilmesi, tedarik zinciri süreçlerinin ve üretilen ürünlerin daha sürdürülebilir hale getirilmesi ele alınmaktadır. Burada yer alan maddelerin, aynı zamanda firmalar için bir kontrol listesi görevini görebileceği ve firmaların eksik oldukları noktaları daha net bir şekilde görüp harekete geçmelerini sağlayabileceği düşünülmektedir. Bu kapsamda sürdürülebilir kurumsal marka ile ilgili ilk özellik, sürdürülebilirliğin en temel işletme stratejisine engtere edilmesini içeren "kurumsal hikaye" dir.

\subsection{Kurumsal Hikaye}

Kurumsal hikâye, kurumsal markanın önemini iç ve dış paydaşlara iletmek, firmanın çalışanları ile bağına da yardımcı olarak rakiplerine karşı bir konum elde etmesi için önerilmektedir (Spear ve Roper, 2013: 2). Hikâye paydaşlar tarafından gerçekçi, samimi, güçlü olarak algılandığında genel olarak kurumsal itibarı arttıracağı belirtilmektedir (Brown, Dacin, Pratt ve Whetten, 2006: 104).

Literatürde kurumsal hikayenin, vizyon (Larsen, 2000; Driscoll ve McKee, 2007; Marzec, 2007; Marshall ve Adamic, 2010), misyon (Larsen, 2000; Dowling, 2006) ve değerlerden (Marshall ve Adamic, 2010) oluşan unsurlar ile stratejik açıdan ele alındığı çalışmalar mevcuttur. Bu çalışmada ise kurumsal hikaye, sürdürülebilirlik perspektifi ile inceleneceği ve sürdürülebilirlik kavramının üst yönetimin güdümünde stratejik bir kavram oluşu nedeniyle, stratejik açıdan ele alınmaktadır. Stratejik açıdan kurumsal hikâye, şirket misyonunu, vizyonunu ve değerlerini birleştirerek kuruluşun stratejisini ifade etmeyi önermektedir (Larsen, 2000; Marzec, 2007: 26; Spear ve Roper, 2013: 6). Kurumsal markanın kurumsal strateji ile bağlanmasının öneminden yola çıkarak, Roper ve Fill (2012), örgütün değerlerinin kurumsal hikâyede açıklanmasını ve kurumsal markanın paydaşların zihninde konumlandırılmasını önermektedir (Spear ve Roper, 2013). Bunun için çekirdek değerler ve inançlar, organizasyonun yaptığı iş ve genel olarak yaşam bağlamında önemli olanı, insanlığa bakışını, toplumdaki rolünü temel düzeyde ifade etmesini sağlar (Collins ve Porras, 1991: 35). Değerler, açıkça, markanın merkezi çekirdeğinin tanımlanmasıyla ilgilidir (Urde, 2003).

Sürdürülebilirlik stratejisinin uygulanmasında bu değerler arasında da uyum olması gerektiği belirtilmektedir (Jablonski, 2015: 852). Bunu destekler nitelikte kurumsal teori bakış açısı da tutarlııı gereği, işletmelerin çekirdek değerleri vasıtasıyla belirttiği sürdürülebilirlik vaadini tutmasının, diğer bir ifade ile vizyon, misyon, strateji ve eylemler arasında uyum olduğunda meşruluk kazanacağını belirtmektedir. Van Riel (1992), organizasyonun kimlik ve imajının stratejisi ile bağlı olduğunu belirtmekte ve bu doğrultuda stratejik ifadelerin imaja yansıdığı ifade edilebilmektedir.

Misyon, vizyon ve değerler, çalışanlara ve diğer paydaşlara sürdürülebilirlik konumu hakkında açık mesaj vermek için resmi ve kapsayıcı unsurlar olarak görülmektedir (Bertels, S, Papania, Papania, ve Graves, 2010). Aynı zamanda bu unsurlar sürdürülebilirliğin stratejik formülasyonu ve çekirdek stratejiye entegre edilmesi için gerekli görülmektedir (Nathan, 2010) Sürdürülebilirliğin bu unsurlara entegrasyonu yönetim kurulu üyelerinden çalışanlara, karar verme süreçlerine sürdürülebilirliği entegre etmelerini sağladığı belirtilmektedir. Sürdürülebilirliğin açık bir şekilde belirtilmesi ise örgütün sürdürülebilirliğe uyumunu teşvik etmektedir (Stranberg, 2009: 18). Örneğin; giyim firması Patagonia, markasını KSS üzerine konumlandırarak 
ve bunu misyonuna ekleyerek paydaşlarının farkında olmasını sağlamıştır "En iyi ürünleri üret, en az zararı ver, ilham vermek ve çevre krizine çözüm üretmek için işi kullan" misyonu, firmanın kurumsal kültürünü sürdürülebilirlik ile uyumlu hale getirerek marka ilişkilerini yürüttüğü gibi paydaşlarıyla birlikte toplumsal ve çevresel koşulların iyileştirilmesine de öncülük etmektedir (York, 2009: 100).

Sonuç olarak sürdürülebilirlik ve meşruluk arasındaki ilişkiye dayanarak (Jennings ve Zandbergen, 1995: 1027), sürdürülebilirlik liderleri vizyon, misyon ve değerlerini sürdürülebilirlik temelli olarak oluştururken, sektördeki rakipleri de meşrulaşmak adına onları taklit edeceklerdir. Buna ek olarak kurumsal teori, vizyon, misyon, değerler ve strateji ve eylemler arasında uyum olduğunda firmanın tutarlı davranışlara sahip olacağını ve bu şekilde meşrulaşacağını belirtmektedir. Tabi kurumsal sürdürülebilirlik alanında meşrulaşmak adına, bu kavram vizyon, misyon ve değerler ile birleştikten sonra, kurumsal marka kapsamında onun, kültür ve imaja da entegre edilmesi önerilmektedir. Aksi halde sürdürülebilirliğin, "yeşil boyama" yapan firmalarda olduğu gibi yüzeysel kalması söz konusu olacaktır. Diğer bir ifade ile en kilit noktadaki paydaşlar olan çalışanlar sürdürülebilirliği iyi özümseyemediğinden, onların iletişim kurduğu başta müşteriler olmak üzere diğer paydaşlar, firma vaadleri ve çalışan davranışları arasındaki tutarsızlığı hissedecektir.

\subsection{Vizyon, Kültür, İmaj}

Hatch ve Schultz (2003)'a gore kurumsal markalamanın üç önemli unsuru vizyon, örgütsel kültür ve kurumsal imajdır. Tıpkı kurumsal teoride işletmelerin verdiği sözü tutması durumunda, diğer bir ifade ile vizyon, strateji ve eylemler arasında uyum gerçekleştiğinde tutarlı ve güvenli (Scott, 1987: 509) olarak algılanacağı belirtildiği gibi, bu üç unsur arasındaki uyum, kurumsal markanın tutarı ılmasını sağlamakta ve işletmenin rekabet avantajı kazanmasına yardımcı olmaktadır (Hatch ve Schultz, 2003). Tutarlı olmak ise, işletmenin meşruluğunu arttırmakta, tüketiciler üzerinde olumlu etki yaratmakta ve bu da pazar payının artmasını sağlamaktadır (Apaydın, 2009: 19). Müşteriler, marka vaadleri, eylemleri ve ürünlerinde tutarlı olan işletmelere güven duymakta ve bu işletmelerin ürünlerini tercih etmektedir. Tutarsız olan işletmeler riskli olarak algılanmakta, bu işletmelerin ürünlerinin çekiciliği azalmaktadır. Ürünlerin kaliteli olması, tek başına müşteri tatmini için yeterli gelmemekte, işletmenin vizyon ve eylemleri arasındaki tutarsızık zayıf kalite algılamasına neden olmaktadır (Erdem, Swait ve Louviere, 2002). Bu durumda, güçlü bir kurumsal marka için üst yönetim tarafından ifade edilen vizyonun uygulamaya geçirilebilmesi adına kurumsal kültür önemli hale gelmektedir.

Kurumsal kültürü meydana getiren normlar, etik kurallar ve değerlerin, çalışanlar tarafından benimsenme düzeyi arttıkça işletme güçlü bir kültüre sahip olmaktadır. Bu kültür sayesinde, çalışanların iş ortamındaki davranışlarına rehberlik edecek kurallar bütünü meydana gelmektedir (Gottlieb ve Sanzgiri, 1996: 1276). Sürdürülebilirlik liderleri meşruluk kazanmak adına, sürdürülebilirlikle uyumlu değerleri (Gottlieb ve Sanzgiri, 1996), çalışanlar arasında dayanışma sağlayarak, onların katıımını artırarak oluşturma çabasına girmektedir (Scott, 1987: 507). Sürdürülebilirlik ile ilgili değerlerin çalışanlar tarafından benimsenmesi ile işletmeler güçlü bir kurumsal marka için vizyonla bağlantılı tutarlı davranışlar sergileyebilir ve kurumsal imaj olumlu yönde etkilenebilir.

Kurumsal imaj, paydaşlarda kuruma ilişkin oluşan görüşler, düşünceler ve izlenimler bütünü olarak ifade edilebilir (Kotler, 2001: 262). Kurumun yapısı, kültür, vizyon, misyon, değerler, çalışanların nitelikleri, liderlerin yaklaşımları gibi birçok faktörden etkilenmektedir (Howard, 1998: 1). Kurumsal imaj, kurumun ne kadar tanındığı, saygın oluşu, değerleri ve rakiplerine göre durumu gibi konulara istinaden şekillenmektedir (Okay, 2005: 245). Kurumların pozitif imaja sahip olması daha fazla kar elde etmeleri anlamına gelmektedir (Bulduklu, 2015: 13). Güçlü bir kurumsal imajın oluşmasında, görsel kimlik unsurları (logo, yazı karakteri vb.), davranış (çalışanların verdiği tepki ve davranışları gibi) ve iletişim (çalışanların birbirleri ve yönetim-çalışan iletişimi gibi) unsurları birlikte ve sinerji içinde olması beklenmektedir (Balta Peltekoğlu, 1997). Kısaca ifade etmek gerekirse sürdürülebilirlik ve meşruluk arasındaki ilişkiye dayanarak sürdürülebilirlik liderleri vizyonlarını sürdürülebilirlik temelli olarak oluştururken, kurumsal marka bağlamında kültür ve imajlarını buna uygun hale getirmeleri gerekecektir. Bu kapsamda gerekliyse kurumsal imajın yeniden markalandırılması ve sürdürülebilirlik ile uyumlu hale getirilmesi söz konusu olabilmektedir. 


\subsection{Kurumsal Yeniden Markalama}

Kurumsal yeniden markalama, paydaşların zihninde farklı bir konum elde etmeyi ve rakiplerden farklı bir kimlik ortaya koymayı temsilen yeni bir isim kullanma durumu olarak ifade edilebilir (Muzellec, Doogan, ve Lambkin, 2003). Kurumsal yeniden markalamayı gerektirecek çeşitli nedenler olabilir. (Stuart ve Muzellec, 2004)'e göre kurumsal yeniden markalamayı gerektirecek içsel nedenler; şirket birleşmeleri, devralmalar ve bölünmeler, yeni odak ya da vizyon, yeni sosyal sorumlu imaj; dışsal nedenler, ekonomik ve hukuki koşullarla ilgili pazardaki değişimdir.

Markalama bakış açısı ile sürdürülebilir kurumsal marka geliştirmek, kurumsal yeniden markalama demektir (Stuart ve Muzellec, 2004; Merrilees ve Miller, 2008). Kurumsal markanın çekirdek değerini yansıtacak uygun bir marka vizyonu, değişen koşullara uygun olmaya yardımcı olmaktadır (Merrilees ve Miller, 2008). Marka vizyonu üst yönetim tarafından (Balmer ve Soenen, 1999) tanımlanmaktadır. Marka vizyonu bir markanın ortaya koymak istediği gelecek ortamı, amacını ve temel değerlerini içermektedir (Chernatony, 2002: 120).

Köklü firmaların isimlerini değiştirmesi söz konusu olmasa da, sürdürülebilir kurumsal markaya geçişte görsel kimlik ve sloganları yeni markaya uygun olarak değiştirilebilir (Camilleri, 2008; Stuart, 2011). Bunun yanında firmaların sürekli kullandıkları sürdürülebilirlik sloganlarını da zaman içinde değiştirmeleri mümkündür. Örneğin Walmart'ın "her zaman daha düşük fiyat" sloganı, sürdürülebilirliğe yalnızca maliyet odaklı ele aldığı görüşü ile eleştirilmiştir. Bu durumda Walmart'ın önünde iki seçenek yer almaktadır. Illk olarak firma, sloganını değiştirmeden çeşitli görsel kimlik unsurları ile paydaşlara mesaj iletebilir. Örneğin; yeşil sertifika logoları ya da basılı reklamlarda basit grafikler gibi. Bunun gibi ipuçları Walmart'ın sloganında yer alan düşük maliyet konumu ile kapışmadığı gibi sürdürülebilirlik ile ilgili gelişmelerini bildirmektedir. íkinci seçenek de, marka mesajının daha sürdürülebilir şekilde konumlandırılmasıdır. Walmart, "Para Biriktir, Daha İyi Yaşa" sloganı bununla bağlantılıdır (Peloza, 2012).

Sürdürülebilirlik ve meşruluk arasındaki ilişkiye dayanarak, sürdürülebilir kurumsal marka yaratımında firmaların paydaşlarına karşı meşruluk sağlayabilmek adına görsel kimliklerinden bazı unsurları değiştirerek kurumsal yeniden markalama yoluna girebileceği söylenebilir. Sürdürülebilir kurumsal marka kapsamında paydaşlar nezdinde meşrulaşmak adına görsel kimlik unsurlarının değiştirilmesinin yanında, paydaşlarla yapılacak işbirliği de oldukça büyük önem arzetmektedir.

\subsection{Paydaşlarla İşbirliği}

Kurumsal teoride üzerinde durulan "çevre", bir kurumun ihtiyaçlarını karşıladığı ve meşruiyetinin tanınması adına kurallarına uymak durumunda olduğu paydaşlarından oluşan bir bütündür. Bu çevrede kurumlar, anahtar tedarikçiler, kaynak ve ürün tüketicileri, düzenleyici kuruluşlar ve diğer kurumlar ile birlikte faaliyet göstermektedir (Dimaggio ve Powell, 1983). Selznick (1948: 28), çevre ile etkileşim halinde olan kurumların, içinde bulundukları çevrenin değişen yapısına uyum sağlayan ve benzeşen organizmalar olduklarını belirtmektedir. Bunun nedenini ise bir kurumun kendi kendine tüm kaynakları temin edememesinden dolayı çevresi ile etkileşime girmesine ve bu etkileşimin zamanla karşılıklı bağımlılık ve benzeşmeyi beraberinde getirmesine bağlamaktadır.

Örgüt ve paydaşlar arasındaki bağın önemli olduğu ve işletmelerin paydaşlarına ve çevresel değişime karşı yanıtlayıcı bir iletişim sergilemesi gerektiği belirtilmektedir (Grunig ve Hunt, 1984). Balmer (2001b), kurumsal markayı paydaşlar ile bir sözleşme olarak görmektedir ve paydaş grupları ve organizasyon arasında organik bir ilişkinin olduğunu tanımaktadır (Gregory, 2010). Buna göre bazı paydaş gruplarının önemi diğerlerinden daha fazla olabilmektedir.

Gregory (2010, s. 66) iletişim stratejilerinin paydaşların gruplarına göre güç/ilgi alanı matrisi ile yapılmasını önermektedir. Buna göre yüksek güce ve yüksek ya da düşük ilgi alanı grubuna dahil olan paydaşların, işbirlikçi çalışma ve daha kapsamlı katııı için fırsat sunacağını belirtmektedir. İşletmelerin, yüksek güce sahip paydaşlarıyla hedefleri doğrultusunda etkileşim kurması, onların diğer paydaşlar nezdinde hedefleriyle uyumlu olarak görülüp meşrulaşmasını sağlayabilir. 
Bu doğrultuda sürdürülebilirlik liderleri, faaliyetlerin güvenilirliğini ve verimliliğini arttırmak adına küçük firmalar, üniversiteler, hükümetler ve 254ctivist organizasyonlar gibi kilit paydaşlarla birlikte çalışmayı tercih etmektedir. Kurumsal teori bakış açısıyla onlar bu şekilde sürdürülebilirlik konusunda dışarıdan gelecek baskıların önüne geçmek ve faaliyetlerini meşrulaştırmayı amaçlamaktadır. Örneğin; Marks \& Spencer yönetim kurulu oluşturduğu Plan A çerçevesinde içlerinde dünyanın önde gelen koruma organizasyonlarından biri olan WWF UK CEO'su, Harward Business School'dan bir profesörün de yer aldığı 9 sürdürülebilirlik uzmanı ile birlikte çalışmıştır. Bunun gibi birçok marka da sürdürülebilirlik uygulamalarının doğruluğunu değerlendirmek ve meşrulaştırmak için bağımsız profesyoneller, kar amacı gözetmeyen kuruluşlar, sertifikasyon kuruluşları ile birlikte çalışmaktadır. Bununla birlikte, sürdürülebilir kurumsal marka kapsamında işletmelerin en kilit roldeki paydaşlarından biri tedarikçilerdir.

\subsection{Tedarik Zinciri ilişkileri}

Plan, kaynak, üretim, teslim ve geri dönüşten oluşan tedarik zinciri sisteminin unsurları, çevresel ve sosyal kriterlerle birleştirildiğinde sürdürülebilir tedarik zinciri yönetiminden bahsedilebilir (World Bank, 2016). Ekonomik globalleşme ile birlikte kurumlar üretim faaliyetlerini, üretim ve iş gücü maliyetlerinin daha uygun olduğu Çin, Brezilya gibi ülkelere taşımıştır (Arndt ve Kierkowski, 2001). Özellikle global markaların, yüksek miktarda üretimi düşük maliyete yaptırması ve global çapta yüksek tüketim oranlarına ulaşması, rekabet avantajı kazanmalarını ve marka gücünün artmasını açıklamaktadır. Örneğin; Gap markası, 1984'ten 1999'a satış gelirlerini \% 24000 arttırmıştır. Dış kaynak sağlama, markalara daha esnek olma imkânı ve maliyet avantajı gibi faydalar sağladığı gibi zehirli ya da illegal üretilen ürünler ve çocuk işçi çalıştırılması gibi faaliyetler de kurumsal marka itibarına zarar verebilmektedir. Artık marka firmalar, artan şekilde kurumsal sürdürülebilirliği adapte edip, zincirlerini yönetmeyi ve işletme hedeflerine ulaşmayı planlamaktadır (Gereffi vd., 2005).

Tedarik zincirinde sürdürülebilirliğe odaklanıp tedarikçilerin faaliyetleri için düzenlemeler getirilmesi marka firmaların faaliyetlerinin meşrulaşmasını sağlamaktadır (Dauvergne ve Lister, 2011). Örneğin, 2009 yılında Greenpeace Nestle'ye karşı bir kampanya başlatmış ve firmayı palmiye ağacı yağı tedarikçileri yoluyla yağmur ormanlarını yok etmekle suçlamıştır. Amaç Nestle'nin marka imajına zarar vermek ve daha sürdürülebilir bir tedarik zincirine sahip olması sağlamaya çalışmaktır. Halbuki firmaların böyle bir duruma maruz kalmadan tedarik zincirini düzenlemesi, tedarik zinciri yoluyla sürdürülebilir kurumsal markayı korumak için önemli işletme meselelerindendir (Camilleri, 2008; Stuart, 2011).

Sürdürülebilirlik liderleri tedarikçilerle derinlemesine işbirliği yaparak, tedarik zincirinde en küçük ayak izine sahip ürünlere doğru hedefler koyabilmektedir. Örneğin, Unilever, ürünlerinin çevresel etkisini yarı yarıya azaltmak için tüm tedarik zincirinin katılımını gerektiren bir hedef açıklamıştır. Walmart ise, ayak izinin büyük çoğunluğunun tedarik zincirinde olduğunu 254abul ederek, ürün paketlemesinin değerlendirilmesinden tedarikçinin sürdürülebilirlik değerlendirmelerine kadar bir dizi duyuru yapmıştır. Sonuç olarak sürdürülebilirlik ve meşruluk arasındaki ilişkiye dayanarak, sürdürülebilirlik liderleri marka itibarını korumak ve paydaşlarına karşı meşruiyet kazanmak adına tedarik zincirlerini daha sürdürülebilir hale getirdiği söylenebilir. Tedarikçilerle işbirliği içinde daha çevre dostu hammadde kullanımı ve sonuçta çevreci ürün dizaynı gerçekleştirilbilir.

\subsection{Sürdürülebilir Ürün Dizaynı}

Kamuoyu baskısı ve sınırlayıcı düzenlemelerle birlikte çevresel düşünceler, dünya üzerinde firmaların yeni ürün dizaynı ve üretimlerini etkilemektedir (Choi, Niesb, ve Ramanic, 2008: 431). Ürün dizaynı global sürdürülebilirliği etkileyen en önemli unsurlardan biri olarak, insanlar tarafından tüketilen ürünler ürün gelişim sürecinin bir çıktısıdır. Özellikle erken dizayn kararları sürdürülebilirlik üzerinde önemli etkiye sahiptir. Bu kararlar yalnızca materyal ve üretim seçimleri ile ilgili olmayıp ürünün taşımasından dağıtımına tüm yaşam döngüsünü içermektedir (Ramani vd., 2010: 1).

Yaşam döngüsünün farklı aşamalarında markalı ürünlerin geri dönüşüm ve atık yöntemi girişimleri firmaya farklı fırsatlar sunmaktadır. Bunun gibi girişimler yalnızca çevresel değil, aynı zamanda 
sürdürülebilirliğin sosyal ve ekonomik boyutlarını da tüketicilerin ihtiyaçlarını karşılayarak devam ettirmektedir (LeBreton vd., 2004). Büyük markalar, bir yandan tüketimi arttırırken, bir yandan da paketlerin azaltılması, kimyasal madde kullanımından uzak durulması, enerji verimliliğinin arttırılması, yenilenebilir enerji kullanımının arttıııması gibi uygulamalarla faaliyetlerini meşrulaştırmaya çalışmaktadır. Sürdürülebilirlik liderlerinin uygulamaları, kurumsal teoride belirtildiği üzere (Selznick, 1948) sektörde yer alan diğer firmaların da aynı uygulamaları benimseyerek birbirleriyle benzeşmelerine neden olmaktadır. Örneğin; en büyük paketli ürün perakendecisi ve üretici Tesco ve Unilever, atıklarının \%100'ünü çöp depolama alanlarından uzaklaştırma hedefini, aynı sektördeki rakipleri Sainsbury, Sobeys ve Asda gibi firmalar da yapmaya ve birbirleriyle benzeşmeye başlamışlardır.

Firmanın sürdürülebilir kimliği ile uyumlu ürün ve hizmetler üretmek sürdürülebilir kurumsal marka ile sürdürülebilir firma olmanın bir parçasıdır (Stuart, 2010). Tabi ürün odaklı olmaktan ziyade sürdürülebilir yaşam tarzı olan tüketicilerin ihtiyaç ve beklentilerini tatmin etmek üzere ve ekolojik olarak sorumlu, sosyal olarak anlamlı, estetik olarak tatmin edici, ekonomik olarak ulaşılabilir, teknolojik yeterli bir ürün olmalıdır (Marchand ve Walker, 2007). Sürdürülebilir ürün kullanımı her müşterinin yaşam tarzına ve hedefine uygun olmayabilir ve her müşteri sürdürülebilir ürünler için daha fazla ödemeye razı değildir. Fakat markaların tüketicilerin tarzlarına daha yakından bakabilmeleri ve böylelikle sürdürülebilirliği anlamlı ve görünüşte doğal yollarla bireylerin tüketimine katmanın yollarını bulmaları tavsiye edilmektedir (Ottman, Stafford, ve Hartman, 2006). Çünkü her ürün inovasyonunda olduğu gibi, üründe yapılacak değişiklikler mevcut müşteri yaşam tarzı ve beklentilerine uygun olmalıdır (Stuart, 2010). Böylelikle markalar tüketicilere duygusal ve sosyal refah sağlama ve post-modern tüketicilerin kimlik oluşturmalarına uyum sağlayacak şekilde sürdürülebilirliği tüketime entegre etmek için bir araç haline gelebilmektedir (Arvidsson, 2008).

Sürdürülebilirlik liderleri, sürdürülebilirliği inovasyon ve yeni ürün geliştirme için bir araç olarak kullanmaktadır. Ürün tasarımlarına yeni hedefler ve kısıtlamalar getirerek daha sürdürülebilir ürünler meydana getirmeye çalışmaktadır. Örneğin; General Electric, yeni stratejisi ve iş modeli olan Ecoimagination isimli girişimi ile bir yandan müşterilerinin çevresel ve finansal performanslarını arttırmalarını hedeflemekte; bir yandan da şirketin büyümesine katkı sağlamayı planlamaktadır. Bu kapsamda çevre dostu ürünler üretmek, paydaşlarla diyalog kurmak, daha temiz bir ekonomiye geçmek amaçlanmaktadır (GE, 2017). Hatta firma bu sürdürülebilirlik stratejisini, "dünyanın en acil enerji ve su sorunlarına yeni dijital endüstriyel çözümler uygulamak" için daha ileri bir aşamaya taşımakta ve rakipleriyle partnerliğe doğru gitmektedir (GE, 2017).

Sonuç olarak sürdürülebilir kurumsal marka bağlamında sürdürülebilirlik liderlerinin meşruiyet kazanmak adına sürdürülebilir ürün dizaynı yaptıkları ve rakiplerinin de onları taklit ederek benzeştikleri ifade edilebilir.

\section{Sonuç ve Öneriler}

Genel olarak bakıldığında sürdürülebilir kurumsal marka, örgütün sürdürülebilirliği, kurumsal hikâyesinden, tedarik zincirine ve ürettiği ürün ve hizmetlere varıncaya kadar tüm süreçlerinde temel değeri olarak vaat ettiği, örgütün toplumun bir parçası olarak çoklu paydaşlar nezdinde meşruiyet kazanmasını ve onların zihinlerinde pozitif bir konum elde etmesini sağlayan bir marka olarak tanımlanabilir. Burada hem kurumsal sürdürülebilirliğin hem de kurumsal markanın çoklu paydaşlara odaklanan yapıları, kurumsal sürdürülebilirlik faaliyetlerinin kurumsal marka ile çoklu paydaşlara iletilmesi ve daha da önemlisi onlarla etkileşim halinde gerçekleştirilerek meşruluğun sağlanması açısından iki kavramın entegrasyonunu gerektirmektedir. Aksi halde, sürdürülebilirliği gerçekten uygulayan firmalar, paydaşların zihninde hak ettikleri gibi bir yer edinemeyecek ve yeşil boyama yapan firmalardan farklarını ortaya koyamayacaklardır.

Çoklu paydaşların gelişen çift yönlü iletişim teknolojileri sayesinde gücü her zamankinden daha fazla artmıştır. Artık paydaşlardan, çevre ve insan sağlı gibi konularda gelen olumsuz sesleri bastırmanın mümkün olmadığı günümüzde, firmaların sürdürülebilir kurumsal marka yaratarak onlarla iletişim ve işbirliği içinde, kurumsal sürdürülebilirlik konusu proaktif bir şekilde yönetmeleri gerekmektedir. Ancak bu şekilde onların nezdinde meşrulaşmak ve daha fazla kazanç elde etmek söz konusu olacaktır. İşte bu çalışmada, sürdürülebilir 
kurumsal marka kavramı kapsamında derlenen özelliklerin, firmaların konuyu gerçekten özümsemesini sağlamak üzere yol gösterici olacağı düşünülmektedir. Aynı zamanda bu özelliklerin firmalar için bir kontrol listesi görevini görebileceği düşünülerek, firmaların eksik oldukları noktaları daha net bir şekilde görüp harekete geçmelerini sağlamak hedeflenmektedir.

Kısaca özetlemek gerekirse çoklu paydaşlar nezdinde meşrulaşmak üzere sürdürülebilir kurumsal marka yaratmaya odaklanan firmaların; (a) sürdürülebilirliği stratejik kurumsal hikayelerine entegre etmeleri, (b) çalışanları odak noktaya alarak sürdürülebilirliği kültüre entegre etmeleri, (c) paydaşların zihninde rakiplerden farklı, sosyal sorumlu bir imaj edinebilmeleri için gerekli olması durumunda yeniden markalama (ör. slogan ve renklerin değişimi gibi) gerçekleştirmeleri, (d) önemli paydaş gruplarıyla sürdürülebilirlik faaliyetleri hususunda işbirlikleri gerçekleştirmeleri, (e) tedarik zincirlerinin her noktasını daha sürdürülebilir hale getirmeleri, ve (f) sürdürülebilir kurumsal markaya uygun olarak, sürdürülebilir ürün dizaynı ile müşterilere değer yaratmaları gerekmektedir.

Sürdürülebilir kurumsal marka kavramı üzerinde uluslararası literatürde birtakım çalışmalar yapılmış olmasına karşın, ne Türkçe ne de yabancı dildeki araştırmalarda konu üzerine bir uygulama gerçekleştirilmemiştir. Bu nedenle bir sonraki çalışmada konu ile ilgili detaylı bir vaka çalışması gerçekleştirilebilir ya da spesifik bir sektördeki firmanın logo, slogan, renkler gibi unsurlardan oluşan görsel kimlik unsurları sürdürülebilir kurumsal marka kapsamında ele alınarak bu konuda yeniden markalama yapıp yapmadığı ortaya çıkarılabilir. Buna ek olarak firmaların sosyal medya ya da diğer mecradaki reklamları ve iletişim çalışmaları sürdürülebilir kurumsal marka açısından analiz edilebilir.

\section{Son Notlar}

1. Bu çalışma, Yard. Doç. Dr. Ebru Gökaliler'in danışmanlığında, Yaşar Üniversitesi Sosyal Bilimler Enstitüsü’nde tamamlanan Zeynep Arslan'ın "Sürdürülebilirlik ve Kurumsal Marka Entegrasyonunda, Sürdürülebilir Kurumsal Marka Kavramı ve Yansımaları" başııkı tezinden türetilmiştir.

\section{Kaynaklar}

Apaydın, F. (2009). Kurumsal teori ve işletmelerin kurumsallaşması. Cumhuriyet Üniversitesi iktisadi ve Idari Bilimler Dergisi, 10(1), 1-22.

Allard, G., \& Martinez, C. A. (2008). The influence of government policy and NGOs on capturing private investment. OECD Global Forum on International Investment.

Arndt, S. W., \& Kierzkowski, H. (2001). Fragmentation: New production patterns in the world economy. Oxford University Press.

Arslan, Z. (2019). Sürdürülebilir kurumsal marka kavramı ve BIST Sürdürülebilirlik Endeksi'ndeki firmaların sürdürülebilir kurumsal marka uygulamaları üzerine bir araştırma. Pazarlama ve Pazarlama Araştırmaları Dergisi, 12(24), 385415.

Arslan, Z., \& Albayrak, R. S. (2019). Sürdürülebilirlik raporlarının kurumsal marka bakış açısı ile analizi: Arçelik örneği. Dokuz Eylül Üniversitesi Sosyal Bilimler Enstitüsü Dergisi, 21(2), 467-492.

Arvidsson, A. (2008). The ethical economy of customer coproduction. Journal of Macromarketing, 28(4), 326-338.

Balmer, J. M. T. (2001). Corporate identity, corporate branding, and corporate marketing: Seeing through the fog. European Journal of Marketing, 35(3/4), 248- 291.

Balmer, J. M. T. (2001b). The three virtues and seven deadly sins of corporate brand management. Journal of General Management, 27(1), 1-17.

Balmer, J. M. T., \& Greyser, S. A. (2003). Revealing the corporation: perspectives on identity, image, reputation, corporate branding and corporate-level marketing. London: Routledge. 9-15.

Balmer, J. M. T., \& Soenen, G. B. (1999). The acid test of corporate Identity management. Journal of Marketing Management, 15, 69-92. 
Balta Peltekoğlu, F. (1997). Kurumsal iletişim sürecinde imajın yeri. İstanbul Üniverstesi Iletişim Fakültesi Dergisi, 0(4), 125-146.

Bansal, P., \& Hoffman, A. J. (2011). The Oxford handbook of business and the natural environment. http://www.oxfordhandbooks.com/view/10.1093/fordhb-9780199584451 (Erişim Tarihi: 2 Ocak 2014).

Barrow, M. (2013). Optimising the value chain: Survival of the fittest. http://www.carbontrust.com/news/2013/08/optimising (Erişim Tarihi: 10 Ocak 2016).

Baumgartner, R., J., \& Ebner, D. (2010). Corporate sustainability strategies: Sustainability profiles and maturity levels. Journal of Sustainable Development, 8(2), 76-89.

BCG, C., \& MIT, S. M. (2011). Sustainability: The 'embracers' seize advantage. MIT Sloan Management Review. https://sloanreview.mit.edu/projects/sustainability-the-embracers-seize-advantage/ (Erişim Tarihi: 7 Nisan 2014).

Belz, F. M., \& Riediger, B. S. (2009). Marketing strategies in the age of sustainable development: Evidence from the food industry. Business Strategy and the Environment, 19(7), 401-416.

Bertels, S., Papania, L., \& Papania, D. (2010). Embedding sustainability in organizational culture: A systematic review of the body of knowledge. Network for Business Sustainability. https://swift.van2.auro.io:8081/swift/v1/6 (Erişim Tarihi: 5 Mayıs 2015).

Brown, T. J., \& Dacin, P. (1997). The company and the product: Corporate associations and consumer product responses. Journal of Marketing, 1(61), 68-84.

Brown, T. J., Dacin, P. A., Pratt, M. G., \& Whetten, D. A. (2006). Identity, intended image, construed image, and reputation: An interdisciplinary framework and suggested terminology. Journal of the Academy of Marketing Science, 34(2), 99-106.

Camilleri, C. S. (2008). Sharing Yalumba communicating Yalumba's commitment to sustainable winemaking. Corporate Communications: An International Journal, 13(1), 18-41.

Choi, J. Niesb, L., \& Ramanic, K. (2008). A framework for the integration of environmental and business aspects toward sustainable product development. Journal of Engineering Design, 19(5), 431-446.

Christiansen, L. T., \& Askegaard, S. (2001). Corporate identity and corporate image revisited a semiotic perspective. European Journal of Marketing, 35(3/4), 292-315.

Collins, J., \& Porras, J. (1996). Built to last: Successful habits of visionary companies. HarperCollins Publishers Inc.

Czinkota, M., Kaufmann, H. R., \& Basile, G. (2014). The relationship between legitimacy, reputation, sustainability and branding for companies and their supply chains. Industrial Marketing Management, 43, 91-101.

Dauvergne, P., \& Lister, J. (2011). Big brand sustainability: Governance prospects and environmental limits. Global Environmental Change, 22(1), 1-10.

De Chernatony L. (2002). Would a brand smell any sweeter by a corporate name? Corporate Reputation Review, 5(2/3), 114-132.

DeSimone, L., \& Popoff, F. (1997). Eco-efficiency: The business link to sustainable development. Cambridge: MIT Press.

Deephouse, D. L., \& Carter, S. M. (2005). An examination of differences between organizational legitimacy and organizational reputation. Journal of Management Studies, 42(2), 329-360.

Diesendorf, M., (2000), Sustainability and sustainable development. (Ed.) D. Dunphy, J. Benveniste, J, Griffiths \& P. Sutton, Sustainability: The corporate challenge of the 21st century, (ss. 19-37). Sydney: Allen \& Unwin.

Dimaggio, P. J., \& Powell, W. W. (1983). The iron cage revisited: Institutional isomorphism and collective rationality in organizational fields. American Sociological Review, 48(2), 147-160.

Dowling, G. R. (2006). Communicating corporate reputation through stories. California Management Review, 49(1), 82100.

Dyllick, T., \& Hockerts, K. (2002). Beyond the business case for corporate sustainaility. Business Strategy and Environment, 11(2), 130-141.

Dunphy, D., Griffiths, A., \& Benn, S. (2003). Organizational change for corporate sustainability. London: Routledge.

Driscoll, C., \& McKee, M. (2007). Restorying a culture of ethical and spiritual values: A role for leader storytelling. Journal of Business Ethics, 73(2), 205-217.

Epstein, M. J., \& Buhavoc, A. R. (2014). Making sustainability work: Best practices in managing and measuring corporate social, environmental, and economic impacts. San Francisco: Berrett-Koehler. 
Erdem, T., Swait, J., \& Louviere, J. (2002). The impact of brand credibility on consumer price sensitivity. International Journal of Research in Marketing, 19(1), 1-19.

GE, (2017). Ecoimagination at work. http://www.ge.com/about-us/ecomagination (Erişim Tarihi: 1 Mayıs 2017).

Gemmill, B., \& Bamidele-Izu, A. (2002). The role of NGOs and civil society in global environmental governance. (Ed.) D. Esty \& M.H. Ivanova, Global environmental governance: Options and opportunities. (ss.77-100).Yale University

Gerber, P., Steinfeld, H., Henderson, B., Mottet, A., Opio, C., \& Dijkman, J. (2013). Tackling climate change through livestock: A global assessment of emissions and mitigation opportunities. Food and Agriculture Organization of the United Nations (FAO), Rome. http://www.fao.org/3/a-i3437e.pdf (Erişim Tarihi: 15 Nisan 2015).

Gereffi, G., Humphrey, J., \& Sturgeon, T. (2005) The governance of global value chains. Review of International Political Economy, 12, 78-104.

Gottlieb, J. Z., \& Sanzgiri, J. (1996). Towards an ethical dimension of decision making in organizations. Journal of Business Ethics, 15(12), 1275-1285.

Gregory, A. (2010). Involving stakeholders in developing corporate brands: The communication dimension. Journal of Marketing Management, 23(1/2), 59-73.

Grunig, J. E., \& Hunt, T. T. (1984). Managing public relations. New York: Holt. Rinehart \& Winston.

Hahn, T., \& Scheermesser, M. (2006). Approaches to corporate sustainability among German companies. Corporate Social Responsibility and Environmental Management, 13(3), 150-165.

Hatch, M. J., \& Schultz, M. (2001). Bringing the corporation into corporate branding. Submitted to European Journal of Marketing, 1-27.

Hatch, M. J., \& Schultz, M. (2003). Bringing the corporation into corporate branding. European Journal of Marketing, 37(7/8), 1041-1064.

Howard, S. (1998). Corporate image management: A marketing discipline for the 21st century. Sigapore: ButterworthHinemann.

Hulberg, J. (2006). Integrating corporate branding and sociological paradigms: A literature study. Journal of Brand Management, 14(1/2), 60-73.

Jablonski, A. (2015). The concept of sustainable strategy implementation. Sustainability, 15847-15856.

Jennings, P. D., \& Zandbergen, P. A. (1996). Ecologically sustainable organizations: An institutional approach. The Academy of Management Review, 20(4), 1015-1052.

Jones, R. (2010). Corporate branding: The role of vision implementing the corporate brand. Innovative Marketing, 6(1), 44-57.

Kotler, P. (2001). Marketing management. Boston: Pearson.

Lawer, C., \& Knox, S. (2004). Reverse-market orientation and corporate brand development. Working Series, Cranfield University School of Management.

Larsen, M. H. (2000). Managing the corporate story. (Ed.) M. J. Schultz, M. Hatch, \& M. H. Larsen, The expressive organisation (ss.196-207). Oxford: Oxford University Press.

Leitch, S., \& Richarson, N. (2003). Corporate branding in the new economy. European Journal of Marketing, 37(7/8), 1065-1079.

LeBreton, W., Casavant, T. T., \& Cote, R. (2004). Small-scale eco-industrial networking: Interorganisational collaboration to yield system wide benefits in communities. Progress in Industrial Ecology, an International Journal, 4(1), 432453.

Lindgreen, A., Xu, Y., Maon, F., \& Wilcock, J. (2012). Corporate social responsibility brand leadership: A multiple case study. European Journal of Marketing, 46(7/8), 965-993.

Marshall, J., \& Adamic, M. (2010). The story is the message: Shaping corporate culture. Journal of Business Strategy, 31(2), 18-23.

Marzec, M. (2007). Telling The corporate story: Vision into action. Journal of Business Strategy, 28(1), 26-36.

Merrilees, B., \& Miller, D. (2008). Principles of corporate rebranding. European Journal of Marketing, 42(5/6), 537-552.

Muzellec, L., Doogan, M., \& Lambkin, M. (2003). Corporate rebranding an exploratory review. Irish Marketing Review, $16(2), 31-40$.

Nathan, M. (2010). Lighting tomorrow with today': Towards a (strategic). International Journal of Sustainable Strategic Management, 2(1), 29-40. 
Okay, A. (2005). Kurum kimliği. İstanbul: Kapital Medya Yayınevi.

Ottman, J., Stafford, E. R., \& Hartman, C. L. (2006). Avoiding green marketing myopia: Ways to improve consumer appeal for environmentally preferable products. Environment: Science and Policy for Sustainable Development, 48(5), 22-36.

Peloza, J. (2012). Sustainability: how stakeholder perceptions differ from corporate reality. California Management Review, 55 (1), 74-97.

Porter, M., \& Kramer, M. (2006). Strategy and society: The link between competitive advantage and corporate social responsibility. Harvard Business Review, December 2006 issue, 1-13.

Ramani, K., Ramanujan, D., Bernstein, W., Zhao, F., Sutherland, J., Handwerker, C., Choi, J., Harrison, K., \& Deborah, T. (2010). Integrated sustainable life cycle design: A review. Journal of Mechanical Design, 132(9), 1-15.

Roca, L. C., \& Searcy, C. (2012). An analysis of indicators disclosed in corporatesustainability reports. Journal of Cleaner Production, 20, 103-118.

Roper, S., \& Fill, C. (2012). Corporate reputation, brand and communication. Harlow, Essex: Pearson PLC. https://www.research.manchester.ac.uk/portal/en/publicationscoporate-reputation-brand-communication (Erişim Tarihi: 24 Kasım 2017).

Schwartz, M. S., \& Carroll, A. B. (2008). Integrating and unifying competing and complementary frameworks. The search for a common core in the business and society field. Business Society, 47, 148-186.

Scott, W. R. (1987). The adolescence of institutional theory. Administrative Science Quarterly, 32, $493-511$.

Selznick, P. (1948). Foundations of the theory of organization. American Sociological Review, 13, $25-35$.

Spear, S., \& Roper, S. (2013). Using corporate stories to build the corporate brand: An impression management perspective. Journal of Product \& Brand Management, 22(7), 491-501.

Stuart, H. J. (2011). An identity-based approach to the sustainable corporate brand. Corporate communications. An International Journal, (16), 139-149.

Stuart, H. J. (2013). Positioning the corporate brand as sustainable: Leadership de rigueur. Journal of Brand Management, 20(9), 793-798.

Stuart, H. J., \& Muzellec, L. (2004). Corporate make-overs: Can a hyena be rebranded. Journal of Brand Management, $11,472-482$.

Urde, M. (2003). Core based corporate brand building. European Journal of Marketing, 37(7/8), 1017-1040.

Van Riel, C., \& Balmer, J.M.T. (1997). Corporate identity: The concept, its measurement and management. European Journal of Marketing, 31(5), 340-355.

Vertandix, (2011). Link sustainability to corporate branding. Online Report. https://www.environmentalleader.com/2013/04/link-sustainability-to-corporate-branding-verdantix/ (Erişim Tarihi: 10.10.2016).

World Bank, (2016). Guidance notes on tools for pollution management. http://siteresources.worldbank.org/INTRANETENVIRONMENT/Resources/Sustainability-in-SupplyChain.pdf (Erişim Tarihi: 19 Nisan 2016).

York, J. G. (2009). Pragmatic sustainability: Translating environmental ethics into competitive. Journal of Business Ethics, 85(1), 97-109. 
This Page Intentionally Left Blank 